University of St. Thomas, Minnesota

UST Research Online

\title{
Should I Stay or Should I Go? Identity and Well-being in Sensemaking About Retention and Turnover.
}

\author{
Teresa Rothausen \\ University of St. Thomas, tjrothausen@stthomas.edu \\ Kevin E. Henderson \\ University of St. Thomas, Minnesota, Hend7407@stthomas.edu \\ James K. Arnold \\ University of St. Thomas, jim.arnold@goldengate.net \\ Avinash Malshe \\ University of St Thomas, amalshe@stthomas.edu
}

Follow this and additional works at: https://ir.stthomas.edu/ocbmgmtpub

Part of the Business Administration, Management, and Operations Commons

This Article is brought to you for free and open access by the Management at UST Research Online. It has been accepted for inclusion in Management Faculty Publications by an authorized administrator of UST Research Online. For more information, please contact asle4660@stthomas.edu. 
Journal of Management

Vol. XX No. X, Month XXXX 1-29

DOI: $10.1177 / 0149206315569312$

(C) The Author(s) 2015

Reprints and permissions:

sagepub.com/journalsPermissions.nav

\title{
Should I Stay or Should I Go? Identity and Well-Being in Sensemaking About Retention and Turnover
}

\author{
Teresa J. Rothausen \\ Kevin E. Henderson \\ James K. Arnold \\ Avinash Malshe \\ University of St. Thomas
}

\begin{abstract}
Explanations of turnover from extant management research focus on the what (content) and how (process) of turnover. This study engages a sensemaking framework to explore the why (meaning) for employees of quitting or staying at an employing organization, in order to add a new layer to our understanding of retention and turnover. Analysis of data from in-depth interviews with leavers and stayers, both post hoc and in situ, using grounded theory methods, reveals identity and well-being assessment sensemaking cycles, which occur periodically or when threat to core elements of identity and well-being across life domains is perceived. Core elements of identity and well-being include purpose, trajectory, relatedness, expression, acceptance, and differentiation. Perceived threat to identity and well-being across life domains leads to varying levels of psychophysiological strain, coping with threat and strain, and reassessment, often in escalating cycles resulting in turnover and continuing into new jobs. Lack of threat to, or facilitation of, identity and well-being, and successful coping result in retention. Overall, these findings suggest that from the perspective of the actors "being retained" or "turning over," these phenomena are part of a deeply felt quest for positive, congruent identity and
\end{abstract}

\footnotetext{
Acknowledgments: This research was partially sponsored by the Center for Ethical Business Cultures and its member organizations (www.cebcglobal.org) as part of a larger study on retention. An early version of this work was presented at the 2010 Academy of Management annual meeting in Montreal, and a version based on additional data collection was selected as a featured top poster and presented at the 2012 Society for Industrial and Organizational Psychology annual meeting in San Diego. The authors thank participants and copresenters in those sessions for helpful comments and Carolyn Olson for research assistance. We are grateful to John Hollenbeck and Kevin Corley for suggestions on an earlier version of this manuscript and to members of the research workshop series at the Carlson School, University of Minnesota, and the Opus College of Business, University of St. Thomas, for helpful suggestions. Finally, we acknowledge the impact of our colleague, Dr. Susan Heckler (1955-2011), on the development of this manuscript through her profound influence on us and dedicate this research to her.
}

Corresponding author: Teresa J. Rothausen, Department of Management, Opus College of Business, University of St. Thomas, 1000 LaSalle Ave., TMH 443, Minneapolis, MN 55403, USA.

E-mail: tjrothausen@stthomas.edu 
psychological well-being across life domains. Along with other research, these findings suggest that when people consider leaving jobs, it may invoke a liminal identity stage, which makes family and other life domains salient to turnover decisions. Implications for research on retention, turnover, identity, well-being, work-life, and psychophysiological health in organizations, as well as practical implications, are discussed.

Keywords: identity; well-being; threat; facilitation; health; retention; turnover; work-life; sensemaking; grounded theory

He said, "I've had it! To the passenger who called me a mother******, **** you! I've been in this business for 28 years and that's it. I'm done."

— Gardner (2010)

On Monday, August 9, 2010, JetBlue flight attendant Steven Slater reacted strongly to a belligerent customer during the deplaning process. This passenger started to retrieve her luggage from an overhead bin before it was safe to do so, and when Mr. Slater asked her to desist, she cursed him. Mr. Slater then "grabbed his bags - and two cans of beer from the galley - and popped the lever for the plane's inflatable emergency chute," then slid to the tarmac in a dramatic case of voluntary turnover (Gardner, 2010). Press reports afterwards suggest that he had experienced similar trials over a 20 -year period yet had not quit (Kilgannon \& Robbins, 2010).

This widely reported incident of voluntary turnover may not be typical, but it highlights aspects of the phenomena not well explained by extant models. Dominant models in management literatures focus on the what (content) and how (process) of turnover (Maertz \& Campion, 2004), are generally sequential and linear (Boswell, Boudreau, \& Tichy, 2005), and focus on job dissatisfaction as the primary cause, with important modifications adding discrete events or shocks to the system (T. W. Lee, Mitchell, Holtom, McDaniel, \& Hill, 1999) and job embeddedness (Felps, Mitchell, Herman, Lee, Holtom, \& Harman, 2009). This does not fully explain Mr. Slater's exit, however, as he had experienced similar content and shocks, in a similar process, and was similarly embedded previously, yet this incident led to him quitting. Why?

Reviews indicate that researchers are not content with the predictive power of current turnover models and that research using the dominant model explains only $10 \%$ to $25 \%$ of voluntary turnover (Boswell et al., 2005; Hom, Mitchell, Lee, \& Griffeth, 2012; Maertz, 2012; Russell, 2013). Its bounds may be due in part to reliance on limited frameworks, types of data, and methodologies (Russell). For example, there is little use of leavers' self-reports and in-depth exit interviews (Bergman, Payne, \& Boswell, 2012; Maertz). In this study, we use these types of data and grounded theory to explore the sensemaking of the actors involved in retention and turnover. In doing so, we uncover underexamined cognitive, emotional, and behavioral elements affecting turnover, which exist in complex interrelationships, while also beginning to fill a significant methodological gap in turnover research.

The major contribution of our research is our finding that from the perspective of the actors of turnover, it is part of a complex process of building well-being and identity resources. The process comprises cycles of assessment of facilitation or threat from the job to primary 
elements of identity and well-being, with threat resulting in strain, and coping with threat and strain. Unsuccessful coping results in repeated cycles. Ongoing cycles last from days to decades, during which individuals stay in jobs, and continue across turnover incidents.

Implications include the following: Escalating strain with repeated cycles of unsuccessful coping may explain why shocks and levels of job dissatisfaction affect different individuals differently, and the same individual differently at different times; when people consider turnover, it invokes a liminal identity period, in which other life domains become salient in turnover decisions; the "sense that is made" of staying or quitting affects future experiences of retention and turnover; and employees feel strong emotional pulls toward both staying and leaving simultaneously, evoking the strong feeling behind The Clash song title line, "Should I Stay or Should I Go?"

\section{Contemporary Turnover Concerns}

Turnover has been a focus of research for a century and continues to be of interest as a result of its impacts on organizations and workers. Voluntary turnover is costly to organizations when good performers leave, and turnover negatively affects performance for most organizations, especially when quality or customer service is important and when managers and leaders leave (Park \& Shaw, 2013). Job and organization transitions are also significant for workers (Feldman \& Ng, 2007), involving shifts in their self-concepts (Ibarra \& Barbulescu, 2010; Pratt, Rockmann, \& Kaufmann, 2006) and affecting their families (Lyness \& Judiesch, 2001).

Recently, researchers have pointed out that we need to learn more about states distal to turnover (e.g., Boswell et al., 2005; Hom et al., 2012). Before exploring additional determinants of turnover, however, we believe it is important to deeply understand the perspectives of those "being retained" or "turning over" and, specifically, the meaning individuals ascribe to staying or quitting. Although staying or quitting is a worker behavior, the assumptions about what causes it, which underlie many extant models, may too often have focused on organizations at the expense of meaning to workers in their lives, as may be true in other management and psychology literatures (Budd, 2011; Gephart, 2004; Weiss \& Rupp, 2011).

Individuals make sense or meaning when something unusual happens, especially when it involves decisions they themselves have made or their own action or inaction (Sonenshein, DeCelles, \& Dutton, 2014; Weick, Sutcliffe, \& Obstfeld, 2005). Thus, sensemaking is likely especially significant in a major decision, such as voluntary turnover. The same situation may lead to staying or quitting, depending on sensemaking processes. Because sensemaking accesses only conscious awareness, it reveals plausible, rather than completely accurate, explanations of actions or inactions (Weick, 1995). However, perception and plausibility directly affect behavior and can add to our understanding of organizational behaviors (Sonenshein et al.).

Understanding processes in employees as they consider turnover may better equip managers to recognize and address turnover through retention management, a practice increasingly important in organizations (Posthuma, Campion, Masimova, \& Campion, 2013). Frustrated desire to turnover may have even more deleterious effects on organizations and individuals than does turnover itself, and this has been increasingly recognized in organizations (e.g., Korkki, 2013; Picoult, 2010). As researchers have suggested, 
Maybe we would be better off predicting turnover intentions rather than turnover behavior. . . Organizations have a better chance of changing behavior if they can intervene before the intentions manifest themselves. And, [turnover intentions have] implications for other workplace behavior. (Bergman et al., 2012: 867)

The widespread response to the memorable exit of Mr. Slater from JetBlue illustrates this potential impact and is perhaps more alarming than the turnover incident itself, which could be viewed as idiosyncratic. Later in the month in which he quit,

Slater [became] an unlikely folk hero in the U.S. . . A string of pages had been set up in tribute to him on the Facebook website, with many social networkers admiring his grand exit. (Carey, 2010)

The glee with which other workers embraced Mr. Slater's spectacular exit suggests that even short of turnover, there is much to be gained from understanding workers' sensemaking about why they stay or quit, and attitudes toward turnover that exist in them prior to actual turnover.

\section{Extant Dominant Model of Turnover}

Most management turnover research is based on March and Simon's (1958) theory positing two primary drivers, the desirability and ease of leaving, and perhaps even more on Mobley, Griffeth, Hand, and Meglino's (1979) operationalization of these elements as job dissatisfaction and levels of alternatives, respectively (Hom et al., 2012; Russell, 2013). In addition, researchers have studied kinship ties (e.g., Blegen, Mueller, \& Price, 1988), embeddedness in jobs and communities (e.g., Felps et al., 2009), and shocks to the system (e.g., T. W. Lee et al., 1999). Alternatives have been measured chiefly by proxies, such as labor market conditions, rather than by attributes of the alternatives themselves.

Thus, the content, or what makes people think about leaving, has most often been operationalized as job dissatisfaction, supplemented by proxies for alternatives and limited other work and nonwork considerations. By implication, given alternative jobs, people may leave because they perceive the potential for satisfaction with new jobs is greater than with current jobs (T. W. Lee et al., 1999). Advances built on the Mobley model posit different paths to turnover taken by different types of leavers; T. W. Lee et al. propose five such paths, Maertz and Campion (2004) four, and T. H. Lee, Gerhart, Weller, and Trevor (2008) four types of leavers. Others suggest that strong and poor performers experience turnover differently (Salamin \& Hom, 2005; Shaw, Dineen, Fang, \& Vellella, 2009). These paths are differentiated by what motivates turnover-for example, chronic dissatisfaction, an emotion, or a specific event-but are similar in that all involve a relatively linear process with primary causes and stages that end in turnover.

\section{Making Sense of Turnover}

Sensemaking has been characterized as comprising sense and making, that is, the meaning that is made and the making of the meaning (Weick, 1995). Sense is analogous to "the what" or content and making to "the how" or process. Thus, understanding the meaning employees make about why they stay or quit may suggest new directions for content and process in 
turnover models. Budd (2011) argues that organizational leaders and researchers in the 20th century have emphasized a limited number of conceptualizations of work meanings, specifically, economic and transactional meanings over psychological, relational, and social meanings, which has resulted in partial explanations of work-related phenomena in management and other research literatures. If this is true, exploring workers' sensemaking about retention and turnover directly should reveal additional elements of meaning not currently emphasized.

Thus, sensemaking frameworks and qualitative methodologies are promising for addressing important gaps in research and, specifically, the internal processes of individuals considering turnover. Not everyone who experiences dissatisfaction and shocks leaves, and to the extent key shocks have been identified - for example, T. H. Lee et al. (2008) identified unsolicited job offers, promotions, changes in marital status, transfers, firm mergers, and downsizing - not everyone who experiences them leaves, even in a tight labor market. We believe this may be due in part to different meanings ascribed by workers to similar content, shocks, and processes. The purpose of this research was to explore these questions. Extant turnover models are based on common foundational assumptions and methods, and sensemaking and grounded theory allow for investigation of understudied aspects of phenomena in order to build new or expand extant theory (Creswell, 2007). In sum, we wanted to understand the processes individuals go through in making sense, and the content of the sense they make, as they consider turnover.

\section{Method}

We used grounded theory methodologies, which allow a comprehensive understanding of complex issues by allowing informants to tell their stories unencumbered by what researchers may expect to find or what is in the literature (Creswell, 2007).

\section{Informants and Data Collection Process}

We obtained data from 59 informants primarily using in-depth interviews (53 informants) supplemented by two focus groups ( 3 people each for 6 additional informants). We used the theoretical sampling technique, which is a nonrandom sampling technique wherein researchers select a diverse set of theoretically relevant informants that allows them to dig deeper and gain greater understanding of issues and to develop or expand theory (Creswell, 2007).

Access to voluntary leavers was obtained through collaboration with four organizations and through authors' networks. Nine informants left a manufacturing company (Informants 1-9), 8 left an employee services company (Informants 10-17), 15 left an insurance company (Informants 18-32), 12 left a publishing company (Informants 33-44), and 15 additional informants, each from a different organization, were recruited through the authors' professional and personal networks; of these 15 informants, 6 had left various sized organizations in various industries (Informants 45-50), and 9 had not left jobs in over 5 years (stayers) and were employed in various sized organizations in various industries (Informants 51-59). Interviewing leavers about their experiences as stayers in current work situations and interviewing long-term stayers allowed us to collect in situ as well as post hoc data (Snow \& Anderson, 1987). In reporting examples below, we identify each informant by these numbers to ensure confidentiality. 
We selected informants 1 through 44 from lists of employees who volunteered for the study, and who had quit during the past year, from each of the companies. We had limited information about positions and demographics, which allowed us to begin selection consistent with the theoretical sampling technique. Following recommendations to sample broadly to build grounded insights (Corbin \& Strauss, 2008), we began by selecting informants diverse with respect to technical specialties and organization levels, as well as sex and age, because these factors affect turnover and career-related decisions (Feldman \& Ng, 2007; Lyness \& Judiesch, 2001).

After our analysis of initial interviews, we followed an analytical trail (Corbin \& Strauss, 2008; Silverman \& Marvasti, 2008); that is, we identified key concepts, which directed us to select additional informants. Several examples follow. Our first informants were selected to represent diversity on factors shown to affect career decisions. When analyses revealed the importance of identity, we wondered whether this was due to interviewing professional and technical workers, so we added directors and managers and line and support workers. In order to ensure that there was nothing about the four companies that would lead to certain findings, we expanded our sampling into our personal and professional networks to include other types of professions and organizations. As we realized that similar processes were operating for informants in their current jobs as well as those they had left, we added informants who had not left jobs in over five years (long-term stayers). In our final interviews, we saw repetition and confirmation of conceptual categories, which indicated that we had reached theoretical saturation, and we therefore stopped data collection (Creswell, 2007).

Informants represent diverse specialties, professions, and levels from executives to assistants. Of the 46 who reported age, informants ranged from 20 to 58 years old, with an average age of $40 ; 56 \%$ were women; close to one third had no children, one third had two children, and the remaining third had either one or more than two children. Of those who had left jobs, they had gone to large companies (22\%), small-to-midsized companies (32\%), government (4\%), school (14\%), sabbatical or job search (12\%), and homemaking (4\%) or had started their own businesses $(12 \%)$. Informants represent a broad range of tenure in organizations, ranging from under 1 to more than 26 years and averaging 6 years, and diversity of educational levels, consisting of people with high school (20\%), college (56\%), and graduate (24\%) degrees, and include Asian American, Native American, and African American informants, although the majority (89\%) were Caucasian.

Informants included those who had left in part on the basis of preprogrammed decisions (e.g., not getting a promised promotion), those who experienced shocks (e.g., a merger), those who had long-term dissatisfaction, and those who were satisfied with their jobs; $58 \%$ of our informants had new jobs lined up when they quit, 12\% immediately started businesses, and $30 \%$ did not work for pay immediately after quitting. Thus, our informant pool included people who were diverse in terms of factors identified as important to turnover in extant literature.

In addition to primary interview questions, we collected demographic and job information on a paper survey, including the following question: How did your direct supervisor rate your most recent performance in your last evaluation in this job? Forty informants answered, indicating that they had received high (73\%), midrange (25\%), and low (3\%) performance evaluations. In addition, many informants told us of former employers' efforts to retain them and of open offers to return. For the 44 informants who left four specific organizations, we triangulated data on the voluntariness of leaving, confirming the organization report with the 
perception of the informant and our own perception on hearing their stories. This is an important factor for turnover research because of differing uses of the term voluntary (Bergman et al., 2012; Maertz, 2012). Together, this evidence suggests that, generally, our informants were valued and that their turnover was likely dysfunctional for their employing organizations.

\section{Data Collection Methods}

Interviews lasted between 30 and $120 \mathrm{~min}$, averaging $100 \mathrm{~min}$, and were conducted in person at times and places convenient to informants. All interviews were audiotaped, resulting in more than $90 \mathrm{hr}$ of recording, and were typed verbatim by an independent transcriptionist. We conducted two focus groups of 3 participants; each lasted more than $80 \mathrm{~min}$ and was also typed verbatim. Focus groups were conducted for any new insights not captured through interviews and to continue to expand the diversity of the informant pool.

In setting the tone for interviews and focus groups, we consciously created a sense of trust and psychological safety in numerous ways in order to encourage an honest and full accounting of each individual's story. We consciously prepared to be interested in all aspects of informants' stories and nonjudgmental when listening. We maintained silence in order to let informants process and direct the interviews. We assured informants of confidentiality and anonymity orally and in writing. We used warm-up questions to build familiarity before asking primary research questions, which also served to confirm the focal job for the interview, the voluntariness of leaving, and primary tasks as well as other information about jobs left and current jobs or situations in the case of leavers and current jobs in the case of stayers.

Our primary questions were Why did you leave (name of former employer)? and Why did you go to (new situation)? The authors conducted all interviews and focus groups, using these primary questions and the probe questions "Can you give me an example of that?" and "Please tell me more about that." While asking these probe questions, we took care to use questions that were generic and open-ended to encourage in-depth examples and details. In asking about specific details, probes were customized to what each informant had just said. We reflected back our understanding of what informants told us to ensure accuracy and clarity. Overall, this minimized potential interviewer-induced bias and provided informants opportunities to correct anything we had misunderstood. As our analysis progressed (as outlined below), and analytical categories emerged, we asked informants about the categories. On the basis of insights from early analysis, we modified our interview protocol to include the questions How is (new situation) going? and Do you consider leaving? Finally, we modified our questions for long-term stayers to Do you ever consider leaving your employer? and Why or why not?

\section{Data Analysis}

In each step of analysis outlined below, authors independently performed the step and met at regular intervals to discuss their individual results and reconcile any discrepancies. For example, we met after coding the first 5 interviews and then after each set of 10 interviews and similarly in every step. Each author also read all interviews as they were completed and multiple times thereafter. We used QSR International's NVivo software to manage interview and focus group notes, reviewing existing transcripts to identify emerging themes that guided 
subsequent data collection and coding our data in an iterative process, as recommended by Corbin and Strauss (2008) and Silverman and Marvasti (2008). During each step, each author involved kept a journal of codes, categories, themes, and dimensions, which we compared at every meeting. Ongoing refinements were recorded in each author's data coding journal.

We followed five primary data analysis steps. These steps are summarized below, and their outcomes are depicted in Figure 1, which we explain in detail in the Findings section below. Data reliability and analytical validity are important considerations in any qualitative study, and to ensure them, we followed five interrelated procedures when working with our data, as recommended for qualitative research by Silverman and Marvasti (2008: 257-270): refutability, constant comparison, comprehensive data treatment, deviant-case analysis, and respondent validation. At the end of our analysis, we also recoded each interview using the final second-order categories and aggregate dimensions of the theoretical framework indicated in Figure 1.

Following these steps, and integrating the five interrelated procedures into each step, allowed us to put our provisional analytical schemes through the rigors of discrepant cases at each step until we were able to come up with a small set of recursive rules that would incorporate all the data, and no cases refuted our final model. This ensured that our theoretical model is an integrated model that describes retention and turnover sensemaking generally, instead of a process that occurred in only a few cases. In respondent validation, we went back to 15 informants to seek their assistance in validating our findings. Our findings resonated well with these informants, which strengthens validity.

Step 1: Open coding. Three authors independently coded all interviews, meeting regularly, to identify in vivo codes in the data (i.e., concepts represented by language used by informants). For example, one informant indicated an important "corporate mission" that the company drifted away from (37), another highlighted people "we serve" (29), and another mentioned "the mission they set up" (3). In performing this step, we generated hundreds of in vivo codes, all of which we retained and analyzed in Step 2. Space constraints prevent us from reporting these codes comprehensively; however, illustrations of in vivo codes are embedded and highlighted in bold in the quotations in Figure 1.

Step 2: First-order categories. The same three authors independently grouped all in vivo codes into higher level concepts based on underlying similarities and met regularly to identify first-order categories. In this example, we identified that how the reason for the work they were doing became meaningful to them factored into informants' sensemaking about staying or quitting, and we developed a first-order category we labeled "work mission." During this step, we continued to collect data and reread entire informant narratives in an iterative process between data and emerging categories.

We developed a decision rule to set aside first-order categories that reflected job satisfaction because it is already an established predictor of turnover (Hom et al., 2012). Job satisfaction in research is widely acknowledged to be a conceptualization of whether a job is enjoyable and has been conceptualized as separate facet satisfactions or globally for the whole job (Warr, 2007). Therefore, we set aside any emerging first-order categories that had to do with enjoying or not enjoying the job overall or any specific element of the job in order to focus on new ideas. In performing this step, we generated over 100 first-order categories. Space constraints prevent us from reporting these codes comprehensively; however, illustrations are used below and embedded in the examples used throughout the Findings section. In 


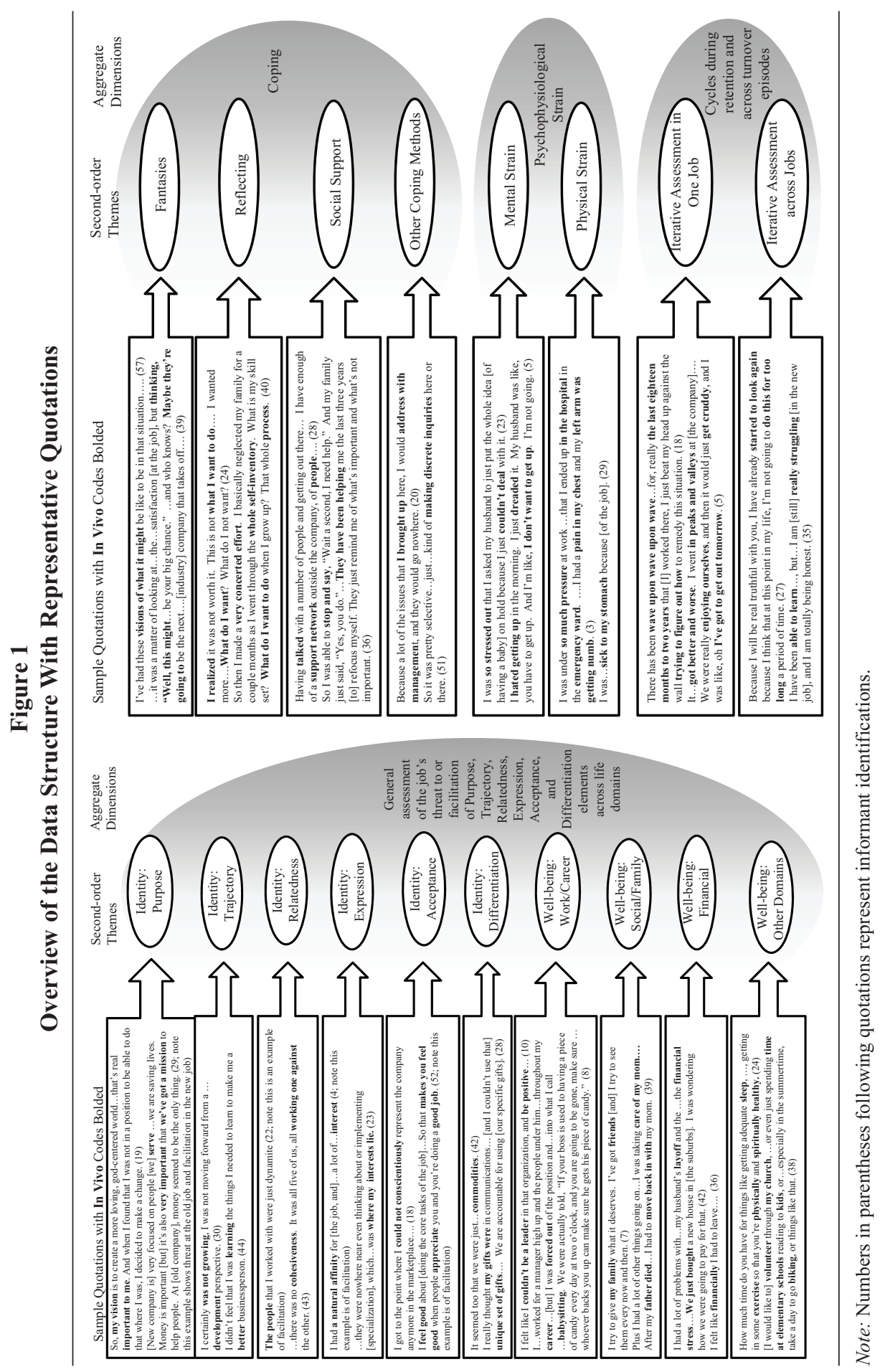


addition, a table with each first-order category listed together with a representative quotation, along with the relationship of each first-order category to results in Steps 3, 4, and 5, is available online in the supplemental material.

Step 3: Axial coding and second-order themes. All authors independently searched for relationships among first-order categories and assembled them into second-order themes and then met to discuss them. Continuing with the example, we identified that combined with other first-order categories, such as "meaning in life," "vision," and "what I was put here to do," this indicated an assessment of threat from the job to a sense of purpose related to identity. We ultimately arrived at 18 second-order themes, which are presented in Figure 1. During this step, we continued to collect data, reread entire informant narratives, and met to discuss these themes.

Step 4: Theoretical similarity. All authors independently examined second-order themes for theoretical similarity and met multiple times to discuss emerging aggregate dimensions. In the continuing example, in combination with five other second-order themes as shown in Figure 1, the analysis led us to conclude that our informants assessed jobs' threat to elements of identity including purpose, trajectory, relatedness, expression, acceptance, and differentiation (PTREAD) periodically or in response to sensemaking cues. Thus, threat to PTREAD elements became one aggregate dimension within our theoretical framework at this point. In this step, in addition to PTREAD elements of identity, we initially identified four other aggregate dimensions: well-being across life domains, coping, mental and physical strain, and iterative assessment of threat and facilitation.

As we continued to reread entire narratives and met to discuss emerging aggregate dimensions, we realized that the six PTREAD elements of identity and well-being across the four life domain categories interacted. Different informants cited threats to different PTREAD elements affecting their well-being in different life domains. Similarly, when discussing threats to well-being, different informants raised different elements of PTREAD. Therefore, at this point, we collapsed these six elements of identity with well-being across four life domains into one aggregate dimension with interacting elements, which we called "assessment of threats to identity elements and well-being across life domains" at this stage. In the ongoing data collection, we asked informants about all 18 second-order themes and the four aggregate dimensions in our theoretical framework (see our respondent validation discussion above). This confirmed that identity and well-being were interrelated for our informants.

Step 5: Theoretical comparisons. After all interviews were completed and the secondorder themes and aggregate dimensions composing our theoretical framework were finalized, we consulted diverse literatures to shed light on them. We engaged in this step because our final second-order themes and aggregate dimensions were quite different from those in extant turnover research. This is often done in qualitative research in order to compare "emerging ideas from the data with existing literatures and vice versa in such a way that each was used to inform interpretation of the other" (Kreiner, Hollensbe, \& Sheep, 2006: 1036).

In this step, we modified labels for three of the four aggregate dimensions in order to acknowledge their similarity to extant constructs in other literatures. The coping label did not change. We found research showing that PTREAD elements are very similar to both identity formation motivations and elements that comprise psychological well-being and that 
iterative assessments of threat or facilitation are very similar to general assessments in stress literatures. Stress theories reinforced the ideas of iterative assessments, and the interaction of strain and coping, but used the terms "psychophysiological strain" and "cycles," which are concepts we also read about in other literatures. At this stage, we changed the label "assessment of threats to identity elements and well-being across life domains" to "general assessment of the job's threat to or facilitation of PTREAD elements across life domains." We changed the label "mental and physical strain" to "psychophysiological strain" and the label "iterative assessment" to "cycles."

\section{Findings}

When informants perceived threat from jobs to their identities and well-being across life domains, it resulted in strain, and cycles of coping with threat and strain, during retention. These cycles often eventually resulted in turnover and continued across turnover incidents. Another way to say this is that from the perspective of the actors involved, turnover is one coping behavior used in a larger process. In this larger process, turnover itself usually follows earlier, unsuccessful coping, and the process continues into the next job. This larger process can be characterized as one of seeking facilitation from a job for identity and well-being in life.

All informants reported general assessments of the job's threat to or facilitation of identity and well-being across life domains. The assessment was "general" in the sense that although it may have been cued by a periodic planned assessment or by a specific event or condition in one life domain, it resulted in an overall or general assessment of identity and well-being across life domains. All but one informant reported experiencing threat. One stayer reported only facilitation of PTREAD elements across life domains; therefore, she did not experience identity and well-being strain or coping. The job facilitated her identity and well-being because she felt she was "the perfect one to do" her job (52). All who reported threat also reported experiencing psychophysiological strain and coping with threat and strain, with the exception of one informant. A leaver with a concrete alternative reported assessing threat and coping with threat without strain. Although she had experienced the job as a threat to identity and well-being, and was coping with the threat, this did not result in strain because she had been building resources to enact a specific opportunity she had in mind. Thus, all informants performed general assessments, and when threat was assessed, it always resulted in coping with threat, and without a plan for leaving the job, strain resulted and coping was with threat and strain.

General assessments most often were of both facilitation and threat, which contributed to strain because it indicated a difficult choice to be made. In quitting a job to ameliorate threat, respondents were leaving elements that facilitated their identity and well-being as well. For many informants, the experience was very emotional, and their descriptions put us in mind of the anguish in the song line "Should I stay or should I go?" The aggregate dimensions of the theoretical framework in Figure 1 also reflect lines in this song, which we use in the headings describing each aggregate dimension below.

Although the findings are explicated below using the organizing structure of Figure 1, the process through which findings emerged was iterative and messy, as described above. Our informants' experiences of the themes and dimensions depicted in Figure 1 were part of a process best described by cycles; the process of sensemaking about retention and turnover is 
one of cycles of coping with threat and strain. Coping is enacted to try to alleviate threat, strain, or both. When coping is successful, a period of latency follows that coping cycle until another assessment of threat leads to another cycle of coping. When coping is unsuccessful, another cycle of coping follows quickly and often repeatedly until it culminates in coping by quitting; we explain this more fully in the section on cycles and the whole model below. Because this process is one of cycles of coping with threat to identity and well-being and the resultant strain, in order to describe the process, it is necessary to first describe these elements, which we do next.

\section{"Exactly Whom I'm Supposed to Be?": Threat to or Facilitation of Identity and Well-Being}

The fundamental "sense made" of turnover and retention was about the balance of jobs' facilitation of and threat to six core elements of identity and well-being across four categories of life domains. Threat and facilitation were identified in general assessment in response to sensemaking cues. In some cases, an event cued general assessment, and in other cases, cues were periodic - an assessment routinely undertaken by the informant alone or with a family member or friend, such as an annual goal-setting retreat. Examples of cues are seen in the sections on coping and cycles below. When the job was perceived as conflicting with pursuit of one or more of the six elements in any of the four categories of life domains, informants experienced threat to identity and well-being, and this always resulted in coping, in most cases with strain proportional to the perceived level of severity of the threat. When the job facilitated one or more of the six elements in any of the four categories of life domains, it engaged informants in their jobs and they wanted to stay.

The six core elements of identity and well-being across life domains are purpose, the sense of meaning, significance, or intentionality in life; trajectory, the sense of past, current, and future coherence in growth and development over time; relatedness, the sense of the quality of connectedness to others and dignity in these relationships; expression, the sense of agency and competence in talents being used for impact on environments and in life; acceptance, the sense of ability to feel positive about oneself, with strengths and limitations, and about decisions and actions taken in life; and differentiation, the sense that one's uniqueness is recognized and valued in social contexts (PTREAD).

Informants spoke of work, family, and financial domains separately, and other domains were often blended together in their responses, including leisure and recreation; physical, mental, and spiritual health; community and citizenship; and education. Therefore, we also blend these other domains when reporting representative quotations in Figure 1. Most informants reported threats to and facilitation of multiple PTREAD elements across multiple life domains. We highlight two verbatim examples for each PTREAD element and life domain category in Figure 1, where original in vivo language is highlighted. Below we highlight a few aspects of our findings that may be less clear from reading these brief examples.

Most examples in Figure 1 are of threat to PTREAD elements, but a few are examples of facilitation. Leavers experienced facilitation along with threat, which caused strain due to tradeoffs involved. One long-term stayer reported facilitation of identity and well-being this way:

[There] is prestige in working where I work. People find it fascinating. People know about it. People want to talk about it. People have an opinion about it. It is definitely a part of my identity. I am [name] who works at the [organization]. (55) 
Although core PTREAD elements are separable, a subset of informants blended elements, especially in cases of threats from the job to expression, acceptance, and differentiation. For example, one informant wanted to be acknowledged and valued for her unique qualities, be able to express that, and feel positive about expressing it. Her explanation below also illustrates the link between identity and well-being and illustrates strain:

I am a very loyal person. I never abuse [privileges]. Never abuse ... I just don't do that. I would never take a day of vacation without marking it down. ... [Because I was treated as if I would], I got real depressed. I had to go to the doctor and I have never been depressed in my life. I mean [I've] always [been a] happy person. (8)

Other informants cited identity holistically. For example, in explaining his transition, one informant said, "I focus[ed] more on ... my true identity and matching my professional identity to who I really am" (46). In some cases, sensemaking about PTREAD elements included consideration of social group identities. For example, our youngest informant said, "Age, and place in life ... where you are right now" was important in his decision to stay at his job (51).

\section{"I'm on My Knees": Psychophysiological Strain}

The prevalence of strain in our data was surprising, given the sequential, rational approach of extant turnover models. The level or intensity of strain was generally congruent with the perceived acuteness of the threat. To illustrate this, we highlight two contrasting stories. Immediately below, we document a story in which relatively low levels of perceived threat were accompanied by relatively low levels of strain, along with quotations from more acute cases; in the section on cycles below, we document a more acute case.

Informant 4 expressed relatively mild perceived threat accompanied by correspondingly mild psychophysiological strain. He felt that "if this was the type of philosophy that the organization was going to adhere to, then it was clear to me then I didn't have a future there" because the philosophy was counter expression of his identity and following the trajectory he wanted. He had needed to find an alternative in the same geographic region because he was in his 50s and at the executive level, where job changes often require relocating, which would have threatened relatedness in the family domain. He said, "I wasn't willing to relocate. I have a son who is a junior in high school. So, I wasn't willing to relocate." He expressed a correspondingly mild level of mental strain from these threats, including anxiety, and also said, "I would say that ... my morale was impacted." He had mild physical strain in the form of low energy and fatigue, saying that "it became a sense of drudgery."

A story of severe perceived threat accompanied by more severe strain is reported in the section on cycles and the whole model below. Here we provide quotations in which informants report relatively severe strain because this was an unexpected finding. Overall, the frequencies and levels of psychophysiological strain were higher than we expected on the basis of extant models. The psychological safety created in our interviews may have allowed this socially undesirable self-admission to surface, which we discuss further below. The following informants are from different organizations and represent a mix of women and men across age categories and professions, and these cases illustrate both mental and physical strains. Although these cases were striking because of the extent of the strain, they were not the only cases in which strain was this high. 
If you keep that up for five years, you're just spiritually and physically ... just killing yourself. ... It wasn't healthy anymore for me to be there. (24)

I mean literally, every night I would come home, probably for the last four or five months and I'd rant and rave at home and then I'd end up crying. ... It took me almost two and a half months [after leaving] to finally lose the tension in my shoulders. (15)

I found myself dreading walking into the building . . . and practically frozen to turn on the computer, knowing there was going to be any number of messages from [my boss] just waiting for me. . . . This isn't the way it was supposed to be. I had . . income. I had severance from [a previous company].... We were in the dollars. Had a very high visibility position. But it just got so wearing and so nerve-wracking. (42)

I almost felt . . . like an abused wife syndrome [survivor]. . . . "If I stay, I'm saying it's okay." . . . It was a weight off my shoulders when I left. . . It's very, very sad, and it really was so frustrating. (18)

One stayer who had experienced strain related to a prior job explained it this way:

I've had positions where I've felt physically sick going to work . . . the closer I got to work, I would just start to feel the knot in my stomach and ... an upset stomach kind of feeling and just, I could almost feel my body sort of resisting, trying to push back on the car. "Don't get any closer" kind of thing. So, it was a physical reaction. (58)

\section{"You Gotta Let Me Know": Coping Through Social Support, Fantasy, and Reflection}

Sensemaking occurs in an ongoing, social process (Weick, 1995). Reflecting this, sense was made of turnover and retention through cycles of coping with threat and strain most often using social support, with fantasy and reflection used to integrate ideas over time. Quitting itself was a way of coping with threat and strain, but it was not usually an early coping strategy, instead coming after other coping failed. This is illustrated further in the next section on cycles.

Our informants coped using social support throughout their processes. Support came from multiple sources, including current and former colleagues, associates, acquaintances in virtual communities, friends, and family members. Fantasy is creative imagining - picturing or visualizing oneself in a situation. Fantasies were of leaving, alternatives, or of staying and were projected far into the future. Informants who fantasized themselves in a situation that then felt "more right," or destined to be, appeared to use this as a way of testing a new potential situation (examples of this are included in the quotes for fantasies in Fig. 1). Reflection occurred in a number of ways, including writing, being coached formally or informally, asking oneself key questions, and forming goals and plans. Informants used reflection to explore their identities and what contributed to their well-being (e.g., see the questions asked in the first quote for reflecting in Fig. 1). Most informants used many different types of coping within these three categories, as well as other types, such as evaluating alternatives, which is part of the extant dominant model of turnover; communicating; negotiating to try to change conditions at work; negotiating in the family domain; and using politics. 
Two examples of each coping category are reported in Figure 1. As with other aspects of our data, we regret that many other rich examples were left out as a result of space considerations. Many informants mentioned all three types of coping but in different parts of the interview, as in these examples from one informant, of social support, reflection, and fantasy, respectively:

I knew a lot about [the new company] because my husband is a part of this group; [I] specifically knew some of the consultants, who were friends of mine.

Really made me stop and think what is important, and what do I want to do with the remaining ten to fifteen years of work that I think that I have?

I have always thought about . . . some sort of a business; it seemed to me that consulting would give me the avenue for a lot of variety and different kinds of challenges. (30)

\section{"One Day Is Fine, the Next Is Black": Cycles and Illustrations of the Entire Model}

Cycles of coping with threat and strain comprise the process informants experienced leading up to turnover. Threats they coped with were to identity and well-being. Therefore, it is difficult to describe cycles without reference to all aggregate dimensions in our model. In some cases, cycles were distant in time, as when successful coping resulted in amelioration of threat and receding strain until the next assessment of threat. When one method of coping was unsuccessful in alleviating threat or strain, and that coping cycle ended, the lack of success was the cue to begin another cycle. Cycles occurred within and across jobs. From informants' perspectives, quitting is one coping behavior, albeit a significant one, rather than an end point in their cyclical process. Informants' retention and turnover sensemaking cycles were spread over long periods of time, in many cases years or even decades, but in most cases were not constant. This is in line with sensemaking generally, in that it was ongoing in response to cues.

This is also illustrated by the case of the JetBlue flight attendant summarized at the beginning of this article. On the surface, Mr. Slater appears to have made a spontaneous turnover decision precipitated by an incident of rude behavior, but it was later revealed that he had experienced cycles of coping with threat and strain for decades. His level of strain appears to have escalated over time to a point where his response to sensemaking cues changed.

Short examples of quotations referring to cycles are reported in Figure 1. However, because this aggregate dimension embeds all others in the model, we use longer respondent stories below to illustrate cycles. These stories also represent how all elements of the model interacted for informants. Both stories, but especially the first one, are representative of the many where perceived threat is at a relatively high level, with correspondingly severe strain levels, in contrast to the story of mild threat and strain in the section on strain above. The first story focuses on cycles within a job and the second on cycles across different jobs.

Cycles within one job. Informant 54 is a mental health professional who is a long-term stayer. Her identity and well-being are both facilitated and threatened by her current job. In the interview, she repeated often how she "always wanted to be a therapist" and told of many 
aspects of facilitation. For example, reflecting facilitation of purpose, acceptance, relatedness, and trajectory elements and overall identity, she explained,

I like what I do. . . . I see the change over a month, three months, or six months . . that's when we change our treatment plans ... it's amazing to see. I mean, it's really, really nice to see. ... Our kids, our families don't demonstrate change very fast. ... [They are] struggling in their lives. ... Helping them to make some progress, that's awesome.

I mean when I got my first business card and it says Family Therapist . . . I [was] so happy. This is what I've always wanted to be! This is what I always wanted to be.

This high level of facilitation of identity and well-being makes the threats she is experiencing stressful to deal with because in order to ameliorate threats and their resultant strain, which was severe, she feels she will have to let go of facilitation elements that are so important to her.

Sensemaking cues in this case are both periodic, she checks in with herself to assess how she is doing in life regularly, and external, including colleagues leaving the clinic where she works, failures in fertility treatments for her and her husband, changes in policies of the larger company of which her clinic is a part, missing events with friends, and other things. All these are cues that lead to her performing general assessments.

Six months ago, she was experiencing cycles a few times a week but is now experiencing daily cycles. Her daily assessments continue to indicate that although her job facilitates many PTREAD elements, increasingly it also threatens acceptance, expression, and relatedness: as a therapist, because she was spending too much time dealing with corporate policies and paperwork; as a wife, because she was too stressed to relate well to her husband; as a mother, because the job didn't give her enough time to pursue fertility issues; and as a friend, because she was too stressed to see friends, as the quotations below reveal. The first quotation is about cues and the second is about cycles of coping with strain and her current level of strain:

I . . . don't get time to talk to my husband. . . Sometimes it really feels like . . What is going on? What are we doing? [And] why am I so irritable if he asks me a simple question? ... I'm so behind, I'm behind all the time. . . . I don't cook anymore, which I really like. . . . I miss friends' birthdays, which never happened before.

At first I thought, okay, I can take care of this. So I started doing meditation, which I still do.... [Next] I went to my general physician and . . . he said take some anti-depressant . . . so, I went to a psychiatrist and she did give me some anti-depressant and some anxiety [medication prescriptions]. . . I did ... start but then it still didn't go away. Then I realized it is not going to go, because it is not-I mean I'm not-my [correct] diagnosis is not anxiety disorder or depressive disorder. That's not what [the problem] is. What it is, is that . . it's not humanly possible [for me to do this job and be who I want to be]. . . . It's always like a burden. It's always ... like huge stones sitting on my chest ... a great heaviness.

Despite the current levels of threat to work, family, and other life domains, and her high levels of strain, she repeated often, "I love my job. . . . I always wanted to be a therapist . . . that's my identity of being," showing her current, ongoing, daily cycles assessing facilitation and threat. She has been actively coping by imagining ideal work situations, as reflected in the first example below; talking to her family and friends about it, as in the second example; and 
trying to communicate and change things at work, as in the third example. These represent her daily coping mechanisms of fantasies, social support, and other coping methods, respectively:

I feel very good that maybe one day ... I won't be this miserable. I would work ... and I go back to my piano and that stuff. This is what I think, that life will be much better. I don't have to worry so much ... I will be happy ... that stone [on my chest] will be gone.

[Most of our] friends ... don't really understand what I do. . . It is very confidential what I do. I don't like to talk about it and that's our . . o oath that we take, and I take that . . . very strictly. But yeah, some closest [colleagues], they know. ... We talk [about these issues].

So, I mean, it's very frustrating. I . . . had some calling for this but I told my supervisor the other day ... this is what I need. This is what I need from you. Nobody is listening.

Her cycles were daily at the time of the interview. This quotation directly addresses how she was experiencing the cycles she was going through at the time of the interview:

When I'm into my work I don't [think about it] . . but every night . . when I come back from the office or wherever my last session is, to home, [I] think or just ponder over what's been happening. ... I kind of think [about this] every evening [now].

Story of cycles across jobs. Our data suggest that going through sensemaking cycles in a job affects cycles in future jobs through learning and accumulated strain. For some of our informants, repeated cycles of coping appeared to speed up, resulting in a cumulative process in which informants learned more about themselves, organizational life generally, what is most important to their identity and well-being, and their ability to cope with threat. For example, one respondent said, "I got to that point . . . I just hit the tipping point more frequently" (46). At the same time, repeated cycles of coping in one job, resulting in coping by quitting, resulted in many cases in higher levels of strain carried into the next job, which could heighten sensitivity to turnover sensemaking cues. We report a second longer narrative below, highlighting how cycles in three previous jobs were affecting current cycles.

Informant 21 is a lawyer who experienced threats to most PTREAD elements across many life domains, but especially work and family, across four jobs. Each job also facilitated different elements of her identity and well-being. As in all interviews, we asked only about the job most recently left and the current situation; however, in explaining why she left, she referred back to two additional jobs before these. This case is a representative illustration of how people engage in a process of seeking PTREAD elements of identity and well-being across life domains and of quitting the job as a coping method to ameliorate such threats to identity and well-being.

She explained that she needed to express her identity as a lawyer and mother but was struggling to find a job that facilitated both. In the first job, she experienced threat to expression in the family domain even before she was a mother. She "couldn't even fathom ... putting the two together." Looking for a job that would allow her expression and acceptance in both the work and family domains, she quit and took a job in a smaller company that was "very flexible for those early years" in her children's lives and allowed for PTREAD facilitation in the family domain. However, she now experienced threat to acceptance and trajectory in the work domain and acceptance in the family domain, as the job "didn't really provide a 
lot of growth" and given the time it took, it began to feel like a threat to both domains. As a result of these threats, she quit the second job and joined the company she had just left when she was interviewed.

On the basis of learning from her cycles of coping with threat in the previous two jobs, she had been really excited to start the next job because she "was surrounded by professionals again and I . . . missed [that] so terribly." This illustrates facilitation of this job for acceptance, expression, and relatedness in direct contrast to the previous job, as was differentiation, in that she felt "very appreciated" for her unique experiences and skills by her supervisor. Thus, cycles of coping with threat in one job affected the meaning of these elements in the new job.

She carried experiences of threat and facilitation from the other two jobs into this job where she again felt acceptance and expression threatened in the family domain. For example, she "wouldn't see anybody at home at all" for several days as a result of going in early and leaving late, and she and her husband "argued one time over who was going to go to work on a Saturday." These and other repeated threats over time caused significant strain; she was "always . . . sleep deprived and crabby" and felt she was "losing a part of myself." She was concerned about trajectory in the family domain because their "lifestyle was heading in directions that we didn't want it to go." Compounding this, she had high stress because she had been trying to find a job that facilitated her well-being and identity across life domains over three jobs now, and this experience threatened acceptance for her, exacerbating strain levels.

In this third job, she coped by negotiating with her manager to "go $80 \%$," but it "just didn't help" with expression and acceptance because "for me to do the type of output I wanted to do, I could not drop back any further" as she would have been "sacrificing myself more" and "not working at the quality level" that she wanted, or as she also more colorfully put it, "doing a crap job just to get out of there." After many cycles of coping with escalating threats and strain, she quit. Her current situation was as "a stay-at-home mom," but she felt threat from that situation to her work domain identity and well-being, and she was again engaged in cycles of coping through fantasy and social support toward a new job or business to move into.

One sensemaking cue she mentioned was getting her income tax forms in the mail every year. She said that she and her husband would joke about a cost-benefit analysis and question "why in the world are we [working so much for so little money]?" They "joked about it" and "sloughed it off," but the next year, they would start "thinking about [it] a lot more seriously and say, 'Really, why are we doing this?"' In addition, unsuccessful coping that did not alleviate threat began to cause more frequent cycles. She indicated that she experienced cycles frequently in her last job where she "struggled with it for about a year" before making the decision to quit because she was "afraid" and wondered, "Would I regret it? Would I miss it?"

Hidden cycles. Even in cases of turnover that at first appeared to be triggered by an event and follow a linear path, many informants later revealed earlier cycles, in some cases going back decades and back to prior jobs, which affected current turnover sensemaking. In a number of cases, informants initially gave one-dimensional, rational, work facet-related or family-related answers to the primary research questions but then added qualifiers, such as "actually it's a bit of a story" (39) or "it's a long history" (15). This may shed light on 
why extant models explain a modest level of turnover. In many cases, our informants' initial responses belied their much more complex, cyclical, and deeply emotional reasons for staying or leaving. We asked about the "bit of story" and "long history," but we had the sense that some informants would not have revealed these deeper levels had we not specifically probed on what they meant by these phrases.

\section{Relationship to Dominant Extant Turnover Models}

In reviewing our findings above, we focused on new concepts. However, in our data, we also found evidence in line with extant models of turnover, which emphasize job dissatisfaction and shocks preceding quitting, and of potential interrelationships between our model and the dominant extant model. In this subsection, we briefly differentiate elements of our model from those in extant models and discuss some evidence for interrelationships.

Elements of identity and well-being, the primary sensemaking categories that emerged from our data, are distinct from job satisfaction. The case of Informant 21, discussed above, illustrates well the differences between job dissatisfaction and threat to identity and wellbeing. This informant made it clear in the interview that job satisfaction had nothing to do with why she left. She "had a great working relationship" with her supervisor, who was "fabulous," "very much family-oriented," and "very understanding." She also noted that it was "a great environment" and that she did not leave "to get away from anything or anyone." It was threats to several specific PTREAD elements across life domains that caused her to leave, not the job or organization. In the opposite situation, a stayer with chronic job dissatisfaction, who had experienced many negative shocks, stayed in part because his job facilitated PTREAD in other life domains:

I can go through a lot of grief at work just knowing that I'm going to have that time with my kids [and for hobbies]. I love the outdoors. I love to camp, ... go boating. (56)

Similarly, threat to specific PTREAD elements was different for our informants from dissatisfaction with job facets. Two comparisons illustrate this. Many individuals were striving for a trajectory anchored in the past and growing into a future across different life domains; this element is very different from the promotion/advancement facet emphasized in the past. Several informants specifically raised not caring about promotion. One man turned down a promotion to take a sabbatical; he spent it "obtaining other skills" because he wanted to grow (26). Another informant explicitly said she was not interested in a promotion but did want to keep learning and growing. She left in part because, "at the time, I had [learned] all I thought I could" (28).

Similarly, threat to relatedness is different from dissatisfaction with one's manager and coworkers. Relatedness is both qualitatively different and broader. Because job satisfaction is enjoyment of a job or job facets, one can "be satisfied" with a manager without feeling relatedness, which is the sense of a quality connectedness. In addition, commonly considered facets are managers and coworkers; however, our informants considered relatedness with clients and customers as well and threat or facilitation from their jobs of relatedness with partners, children, friends, and in a community.

Examples in the work domain with coworkers are shown in Figure 1. Below is an example of facilitation of relatedness with customers in an education-industry job: 
I'm courteous to the parents if there's a parent out there. And the kids, I try to be courteous to them, and fair and firm.... So that makes you feel good. (56)

An example of threat from the job to the family domain comes from a woman whose husband worked at the same company in a different division and who cited her marriage diminishing in quality because she and her husband talked about the organization too much:

As much as we tried not to talk about it, it was what we did for eight hours in the day so you come home and talk about it for [another] two or three hours. . . I needed, and he needed, and our relationship needed to have something besides [this] in it. (5)

Threat to relatedness in the work domain had subthemes, some of which were linked to culture. Relatedness was threatened where people were laid off without kindness or civility while executives still spent lavishly (37), where people were treated poorly (8) or humiliated (24), or where some social identities were not accepted or included (examples in our data set include age, family status, gender, and ethnic identity), even when informants themselves were not the targets of this treatment. These threats varied in perceived severity. The following is representative of more severe threat and reflects the dignity element of relatedness:

It was not a conducive place for being successful. Especially for women. . . There was a little group of [male executives] that sort of hung together [and] there were a number of instances over time where comments had been made to various women in the organization. At one point there was one woman [who] was one of the [Six Sigma] black belts who was pregnant [and] one of [these men] went up and started rubbing her belly and making comments about how she got that way. (14)

In other cases, it was a lack of warmth or humanness that threatened relatedness.

As stated above, although varying considerably in our informants, overall, the frequency and levels of psychophysiological strain, and the length of time spent in ongoing cycles of coping with threat and strain, were higher than we expected on the basis of extant models. This finding may explain why similar levels of job satisfaction and the same shocks affect different people differently and the same people differently over time. Strain is a healthrelated construct, whereas job dissatisfaction is an attitude. The two may be distinct yet interact; their relationship is reviewed elsewhere (e.g., Warr, 2007), and it was beyond the scope of this project to specify this. Nonetheless, on the basis of our data, we expect that job dissatisfaction, levels of identity and well-being strain, and the length of time spent in cycles of coping with threat and strain will better predict turnover together than each will alone, as some research on the role of well-being or life satisfaction in turnover has suggested (e.g., Erdogan, Bauer, Truxillo, \& Mansfield, 2012; Rothausen, Larson, \& Christenson, 2012; Wright \& Bonett, 2007).

\section{Discussion}

We sought to understand the meaning to employees of staying in or leaving employing organizations by adopting a sensemaking framework, which can add richness and depth to the study of organizational phenomena not easily accessed by other frameworks (Weick et al., 2005). As Gephart noted, "The depiction and understanding of the meaning of 
organization members is important in itself and this task is often neglected in organizational research" (2004: 455). We adopted grounded theory methodology and collected data using primarily in-depth interviews and, secondarily, focus groups. As reviewed above, extant turnover models are based on common foundational assumptions and methods, and grounded theory allows for investigation of understudied aspects of phenomena in order to build new or expand extant theory.

Our central contribution is describing turnover and retention from the perspectives of the actors who are quitting or staying as a process of seeking facilitation of identity and wellbeing from jobs. This in turn enables other contributions that address important gaps in understanding turnover processes. Specifically, our findings extend turnover literature by identifying a cyclical process of general assessment of jobs' facilitation of or threat to identity and well-being across life domains, with psychophysiological strain accompanying threat, and coping with threat and strain within and across jobs. These elements together describe employees' thoughts, emotions, and behaviors in turnover and retention processes.

The first category of contributions of this research relates to the finding that turnover is part of identity and well-being processes. Our data show that general assessments of jobs' threat to or facilitation of identity and well-being are central to employees' sensemaking about turnover. Other researchers have explicated identity work and well-being processes (Ibarra \& Barbulescu, 2010; Keyes, Shmotkin, \& Ryff, 2002; Snow \& Anderson, 1987; Vignoles, Ragalia, Manzi, Golledge, \& Scabini, 2006) and have also found that assessments can result in perceptions of threat or benefit to identity (Petriglieri, 2011). Our findings demonstrate that when considering retention and turnover, there are close ties between identity and well-being for individuals. Psychological well-being may result from successfully managing six existential challenges encountered in life (purpose, growth, positive relationships, mastery, self-acceptance, and self-determination; Keyes et al.), and six motives may drive identity construction (meaning, continuity, belonging, efficacy, self-esteem, and distinctiveness; Vignoles et al.). To the best of our knowledge, these research streams developed separately, yet their similarities are striking and overlap the PTREAD categories that emerged from our data across life domains. Thus, our findings suggest that identity and well-being are tightly linked with respect to retention and turnover, and the possibility that they are linked in other phenomena as well.

Although acceptance and expression have been much explored in organizational research, the remaining elements - purpose, trajectory, relatedness, and differentiation (self-determination/distinctiveness) - may be underexplored in organizational behavior research generally (Ashforth, Harrison, \& Corley, 2008; Vignoles et al., 2006) and in turnover research. Increasing interest in meaningful work, callings, prosocial motivation, and eudaemonic job satisfaction may relate to these elements (Budd, 2011; Dik, Duffy, \& Eldridge, 2009; Grant, 2008; Rothausen et al., 2012; Wrzesniewski, McCauley, Rozin, \& Schwartz, 1997).

Our findings are in line with conservation of resources theory (Hobfoll, 1989), which posits that individuals strive to build primary resources to make their lives fulfilling. When they experience surpluses of resources, they experience well-being. When this is threatened and they experience inability to gain these resources, people experience stress or a lack of well-being (Hobfoll). Identity threat has been shown to negatively affect performance, leadership, and change (Petriglieri, 2011), and our data suggest it also contributes to turnover. When jobs threaten identity or well-being, it contributes to turnover, even when job satisfaction is present. 
Our findings also suggest that cross-domain identity and well-being are important in retention and turnover. Identity research primarily explores single life domains, for example, formation of the work identity of doctor (Pratt et al., 2006) or the family identity of father (Roy, 2006). But sensemaking with the self as target may be both analytic (segmented) and synthetic (global). Each individual strives for a coherent sense of self and for a holistic or congruent sense of her or his life across domains (Ashforth et al., 2008), which is also referred to as global identity (Ashforth, 2001). It is threat to this cross-domain identity that was activated when our informants were considering turnover. This finding is striking because so much research on work identities does not indicate cross-domain processes in identity work.

The time immediately preceding, during, and immediately following a role transition can be a liminal period, which is defined as a period during which identity is more ambiguous than usual (Ashforth, 2001). Our data suggest that a threat from the job may cause a liminal period during which cross-domain identity and well-being become salient to turnover and, by implication, perhaps to other organizational decisions and actions. Recently, Ladge, Clair, and Greenberg (2012) found that a liminal period in the family domain for their informants, who were pregnant with a first child, caused work and nonwork identities to be recursively influenced. Our findings suggest another type of liminal period that caused work and nonwork identities to be recursively influenced. This is significant because very little research addresses coevolving identity processes. Their "research provide[d] a rare glimpse into the ways that work and nonwork identities change and are intertwined with one another during liminal periods" (Ladge et al., 2012: 1450), and our research provides another such rare glimpse.

Super (1990) described major life domains from research similar to those in well-being and life satisfaction literatures (Andrews \& Robinson, 1991). In our data, jobs were perceived as threats to or facilitation of all these domains for more than one informant. Previous research has found work-family facilitation (Grzywacz, Carlson, Kacmar, \& Wayne, 2007); our data suggest that similar facilitation can occur for leisure and recreation; physical, mental, and spiritual health; community and citizenship; and education, as the examples in Figure 1 demonstrate.

The second major category of contributions of this research are the findings of the interrelationship of health and the turnover process through strain. This is the first study of which we are aware to uncover strain in a general turnover model, although types of strain have been found in population-specific models (e.g., Kraimer, Shaffer, Harrison, \& Ren, 2012), and one survey of 13,000 employees found that workers most often cited ongoing stress or strain as the primary reason for leaving their jobs (Ruiz, 2007). Strain can run emotionally deep, perhaps because primary resources are threatened (Hobfoll, 1989; Lazarus, 2000). Many of our informants reported that job dissatisfaction played a role as well; however, it was when jobs were perceived as threatening identities or well-being that they developed psychophysiological strain.

Primary appraisals in models of strain are ongoing assessments of stressors, which are also related to identity threat (M. A. Griffin \& Clarke, 2011; Petriglieri, 2011). In our data, when assessments resulted in perceived threat, it affected health at varying levels. Occupational health literatures explicate the process through which psychological factors affect health, including that mild perceived threat results in relatively mild strain and severe perceived threat in more severe strain (Cooper, Quick, \& Schabracq, 2009; Ganster \& Rosen, 2013; Lazarus, 2000), and our data show this for turnover. Threats perceived as acute are 
characterized by intense emotions, such as despair, and are accompanied by physical reactions, such as trembling or vomiting (Kleber \& van der Velden, 2009) and in some cases even severe depression and suicide (Breakwell, 1986). Few of our informants experienced these highest levels of strain; however, many experienced moderate to severe strain, contributing greatly to their turnover.

A third major category of contribution of this research relates to the finding that coping is integral to turnover processes. Leavers reported coping with threat and strain in multiple ways within and across jobs, and many long-term stayers were also coping. As our informants coped, they learned in ways that allowed them to "experiment publicly with provisional identities that serve as trials for possible future selves" (Ibarra \& Barbulescu, 2010: 136), such as through social support, fantasy, and reflection. Our findings are in line with the only other study of which we are aware that found coping integral in turnover (Wright \& Bonett, 1993).

One aspect of what our informants were coping with could be termed "dark side organizational behaviors," such as harassment, discrimination, injustice, negative political behavior, and incivility (R. W. Griffin \& O'Leary-Kelly, 2004). We found evidence of these in the stories told by our informants, as represented in some of the examples above. One model of mistreatment in jobs suggests that sensemaking about such treatment is a cyclical process (Olson-Buchanan \& Boswell, 2008), and our findings suggest that the cyclical processing of mistreatment of self and others may fold into the cyclical considerations of decisions to quit.

Occupational health psychology literatures contain classifications of coping, the most prevalent being problem- and emotion-focused coping; however, this two-category classification has many problems, including confounding of emotion-focused coping with strain (Cooper et al., 2009). Another classification proposed is intrapersonal, interpersonal, and intergroup (Breakwell, 1986). Coping can be characterized as positive (e.g., social support, exercise, use of humor) and negative (e.g., inappropriate venting, alcohol abuse, negative spillover to family). In their review, M. A. Griffin and Clarke note that "a widely accepted definition of the content of coping responses has proved elusive" (2011: 376). Many of our informants used types of coping explicated by all these categories. However, in line with a sensemaking framework, the categories of coping most salient reflect notions of identity, in which possible selves are tested against personal gauges of both authenticity and validation (Ibarra \& Barbulescu, 2010). For our informants, this occurred through social support, fantasy, and reflection.

The fourth major contribution category of our research is the finding that turnover involves cyclical, messy processes comprising emotion, cognition, and behaviors, complementing the more linear nature of turnover paths in extant models. For our informants, cycles of coping with threats lasted from days to decades, with time in between the cycles if coping was successful and with new cycles following quickly if coping was unsuccessful. In retrospect, this cyclical nature is not surprising, given our sensemaking framework and the central roles that emerged for identity, strain, and coping. Coping with strains and identity formation both generally involve cycles (Ashforth et al., 2008; M. A. Griffin \& Clarke, 2011; Pratt et al., 2006), and sensemaking is an ongoing identity-related process (Weick, 1995).

Our findings strongly suggest that researchers expand time frames and span job changes in order to more fully understand turnover. Coping has been defined as thoughts and behaviors used to manage situations that are assessed as threats or stressors, where time spans are important, involving "a cyclical process of resource depletion and repair that unfolds from 
day to day and week to week" (M. A. Griffin \& Clarke, 2011: 360). Similarly, scholars have suggested that preparation for significant role changes related to identity "may begin long before an actual role change" (Ibarra \& Barbulescu, 2010: 137). Our findings support these ideas. Turnover and socialization have been studied as separate phenomena, but our data support the results from at least one other study that the phenomena are portable across jobs (Boswell et al., 2005).

The fifth contribution of this research is the use of a qualitative methodology, which constitutes a methodological contribution. Our data offer a number of advantages that enrich our contributions in ways that would be difficult with quantitative data. We were able to explore retention and turnover together, whereas turnover has generally been studied with less attention paid to those who stay. Use of qualitative methodologies is especially important because of the dual biases toward rational and cognitive explanations for organizational behavior and for organizational perspectives to be featured in much management research (Budd, 2011; Gephart, 2004; Weiss \& Rupp, 2011). When explaining phenomena, individuals may focus on building a positive image in the eyes of their target audience, and in the U.S. business world, rational, emotionally neutral, and transactional explanations are favored (Sonenshein et al., 2014). Many of the stories we heard, from more benign stories of struggling to integrate life domains to more sensitive stories about abusive managers, sexual harassment, and management practices bordering on unethical and certainly uncivil, may not have been revealed by informants without the time we invested in developing psychological safety and trust.

\section{Limitations}

All samples are limited, including ours. Our informants had left or were working for organizations in one geographic region and all but 3 remained in this region upon quitting. The model may not apply to more mobile employees, although findings for expatriates suggest that it may (Kraimer et al., 2012). Another salient limitation is that evidence suggests that most of our informants were strong performers. Leaving differs by performance levels (Salamin \& Hom, 2005; Shaw et al., 2009), so we cannot say whether this model would apply to poor performers. Finally, although 35 of our informants had recently left a job and were working currently, they had been in their current work situations 1 year or less. Only 9 informants had been in their current jobs more than 5 years. However, the average tenure in the job left for leavers was 6 years, so our leavers were longer-term stayers in the previous jobs we asked them about. Nonetheless, we urge caution and replication with long-term stayers before we conclude about the appropriateness of using this model to explain longterm retention.

Perhaps of greater concern is that participation in the study was voluntary, and it is possible informants had a common motivation for participating, which is related to our findings. For example, perhaps they experienced more strain or were more emotional about their turnover experiences. We acknowledge this limitation but argue that the likelihood of finding these dimensions to be central in this diverse of a sample - across organization types, sizes, and level; across reasons for leaving and destinations upon leaving; across age, family status, gender, and job categories; and in leavers and stayers - is unlikely if the phenomena are not important to a broader population of employees. In addition, we suggest that it may be just such emotionally engaged, high performing employees who are the targets of much retention work in organizations. 
Our data were of a single-informant, direct-report nature, primarily composed of in-depth interviews. Social scientists have noted both advantages and limitations to single-informant interviews (Snow \& Anderson, 1987). Interviews can thoroughly tap actors' sensemaking, which has value. Revealing the role of emotions and strain may be more appropriately done with in-depth self-report than with other types of data because researchers may not be reliable judges of emotions in informants (Dimburg, Andreasson, \& Thunberg, 2011). However, a key limitation of sensemaking is that it includes post hoc rationalizations of choices and decisions, and, in fact, all sensemaking is retrospective (Weick, 1995). We partially addressed this by gathering in situ data about current work situations and by interviewing longer-term stayers; however, even this happens after the action of staying. In addition, sensemaking reveals plausible rather than fully accurate explanations. Thus, a boundary condition of our model, as in all sensemaking work, is that it reveals only conscious reasons for leaving.

\section{Implications for Future Research}

Throughout the discussion of contributions and limitations above, we highlighted several areas in need of further research. In addition, our model posits elements that have not been central in turnover research and that should be replicated using multiple methodologies. We hope researchers will explore these findings and encourage careful consideration of social desirability in many organizational settings toward cognitive, rational, and linear explanations.

Although the model describes sensemaking, it remains to be seen whether facilitation of identity and well-being, strain, and coping cycles will predict retention. Longitudinal studies exploring these elements alongside job satisfaction would be valuable. Coping cycles are difficult to study with survey methodologies (Lazarus, 2000), and this is likely true for cyclical coping in this model. One way to study cycles may be with diary methodology, whereby an identified sample of employees is asked to indicate types of coping and levels of strain related to threat, or the balance of facilitation and threat, at either random or regularly scheduled times. Alternatively, researchers could develop measures of the key constructs in our model on the basis of in vivo phrases such as those identified in Figure 1 and items from existing measures from the identity construction, psychological well-being, stress and coping, and psychophysiology literatures, as well as physical indicators of strain, to test these relationships.

Other elements may influence how individuals move through the model. A key set of factors are individual differences, which affect other strain and coping cycles (Lazarus, 2000). Individual differences likely to moderate our model include levels of self-awareness; overall self-evaluation, including of self-assets and self-doubts; psychophysiological resiliency; and openness to new experiences (Breakwell, 1986; Ganster \& Rosen, 2013; Sonenshein et al., 2014).

\section{Practical Implications}

Proactive turnover, retention, and exit management is a growing high performance work practice (Posthuma et al., 2013). Our findings suggest two overarching considerations, as well as some concrete directions, for this practice. First, our findings, when compared to the extant dominant model of turnover, suggest a significant disconnect between organizational 
and economic explanations of turnover and employee sensemaking explanations. Evidence of a disconnect also comes from a large survey that shows stress and strain as the main cause of turnover reported by employees, whereas employers reported dissatisfaction with pay as the main cause (Ruiz, 2007). This disconnect may be due in part to employees' conscious crafting of how they explain turnover to the organizations they are leaving and perhaps to researchers as well. That is, they likely "intentionally [use] language . . . that portrays . . . issues in ways that differ from the individuals' private understandings" (Sonenshein, 2006: 1158).

Second, a general direction for organizations interested in retention management is in the area of sensegiving by managers and leaders to reflect categories important to employees. Sensegiving has been applied to other issues in organizations (Sonenshein et al., 2014; Weick, 1995) and is part of some models of ideal leadership, including transformational and spiritual leadership (Jackson \& Parry, 2011). Sensegiving could be applied explicitly to attempts to influence employees' sensemaking about facilitation of PTREAD elements across life domains. Organizations could be designed, managed, and led to cultivate what could be termed an "ecosystem of engaged retention" that would explicitly consider employees' perceptions of facilitation from their jobs to their identities and well-being. For example, training managers to dialogue about the purposes of employees' work and how it relates to life domains for employees and other people, such as customers, is also in line with findings on prosocial motivation (Grant, 2008). Soliciting life narratives or stories (Ibarra \& Barbulescu, 2010; Roy, 2006) from employees, and tying these thematically to organizational stories, may also lead to perceptions of facilitation (however, this is unlikely to work unless factors of real facilitation are present).

Perceptions of facilitation may be fostered by attention to the job characteristics model such that employees understand the significance of their work (Hackman \& Oldham, 1976). On the basis of our data, careful attention should also be paid to selection and training of managers and leaders. Our data suggest there is lost opportunity for intervention as strain and coping cycles build, and many of our informants mentioned something said by their managers that critically affected their sense of threat or facilitation. Another practical skill for retention management at this level is the ability to accurately read and respond to signs of escalating strain, which evidence suggests can be taught (Dimburg et al., 2011). This ability could be used in selection and development of managers and leaders where retention is desired.

\section{Conclusion}

We know much about turnover, but our overall ability to understand, predict, and manage it is not as strong as it could be due in part to lack of attention to employee perspectives. We find evidence to support the importance to retention and turnover of employees' assessments of threat to or facilitation of identity and well-being, of mental and physical strain, and of coping in repeated cycles over time. The process is complex and involves emotions, cognitions, and behaviors. Understanding the impact of these underexplored aspects should help researchers to more fully model retention and turnover and practitioners to more effectively manage it. By building a model grounded in the experiences of those who stay or leave, we hope to bring research and practice closer to more effective and compassionate management of turnover both for the individuals for whom it is a major life transition and the organizations for which the time, energy, and resources devoted to employee replacement are significant. 


\section{References}

Andrews, F. M., \& Robinson, J. P. 1991. Measures of subjective wellbeing. In J. P. Robinson, P. R. Shaver, \& L. S. Wrightsman (Eds.), Measures of personality and social psychological attitudes: 61-114. San Diego, CA: Academic Press.

Ashforth, B. E. 2001. Role transitions in organizational life: An identity-based perspective. Mahwah, NJ: Erlbaum.

Ashforth, B. E., Harrison, S. H., \& Corley, K. G. 2008. Identification in organizations: An examination of four fundamental questions. Journal of Management, 34: 325-374.

Bergman, M. E., Payne, S. C., \& Boswell, W. R. 2012. Sometimes pursuits don't pan out: Anticipated destination and other caveats: Comment on Hom, Mitchell, Lee, and Griffeth (2012). Psychological Bulletin, 138: 865-870.

Blegen, M. A., Mueller, C. W., \& Price, J. L. 1988. Measurement of kinship responsibility for organization research. Journal of Applied Psychology, 73: 402-409.

Boswell, W. R., Boudreau, J. W., \& Tichy, J. 2005. The relationship between employee job change and job satisfaction: The honeymoon-hangover effect. Journal of Applied Psychology, 90: 882-892.

Breakwell, G. 1986. Coping with threatened identities. London: Methuen.

Budd, J. W. 2011. The thought of work. Ithaca, NY: Cornell University Press.

Carey, B. 2010. The folk hero play book. New York Times, August 14. http://www.nytimes.com/2010/08/15/ weekinreview/15carey.html. Accessed October 17, 2010.

Cooper, C. L., Quick, J. C., \& Schabracq, M. J. (Eds.). 2009. International handbook of work and health psychology (3rd ed.). Chichester, England: Wiley-Blackwell.

Corbin, J., \& Strauss, A. 2008. Basics of qualitative research (3rd ed.). Thousand Oaks, CA: Sage.

Creswell, J. W. 2007. Qualitative inquiry and research design. Thousand Oaks, CA: Sage.

Dik, B. J., Duffy, R. D., \& Eldridge, B. M. 2009. Calling and vocation in career counseling: Recommendations for promoting meaningful work. Professional Psychology Research and Practice, 40: 625-632.

Dimburg, U., Andreasson, P., \& Thunberg, M. 2011. Emotional empathy and facial reactions to facial expressions. Journal of Psychophysiology, 25: 26-31.

Erdogan, B., Bauer, T. N., Truxillo, D. M., \& Mansfield, L. R. 2012. Whistle while you work: A review of the life satisfaction literature. Journal of Management, 38: 1038-1083.

Feldman, D. C., \& Ng, T. W. H. 2007. Careers: Mobility, embeddedness, and success. Journal of Management, 33 : 350-377.

Felps, W., Mitchell, T. R., Herman, D. R., Lee, T. W., Holtom, B. C., \& Harman, W. S. 2009. Turnover contagion: How coworkers' job embeddedness and job search behaviors influence quitting. Academy of Management Journal, 52: 545-561.

Ganster, D. C., \& Rosen, C. C. 2013. Work stress and employee health: A multidisciplinary review. Journal of Management, 3: 1085-1122.

Gardner, D. 2010. World discovers a new hero. Daily Mail. http://www.dailymail.co.uk/news/worldnews/ article-1301798. Accessed October 17, 2010.

Gephart, R. P., Jr. 2004. From the editors: Qualitative research and the Academy of Management Journal. Academy of Management Journal, 47: 454-462.

Grant, A. M. 2008. Does intrinsic motivation fuel the prosocial fire? Motivational synergy in predicting persistence, performance, and productivity. Journal of Applied Psychology, 93: 48-58.

Griffin, M. A., \& Clarke, S. 2011. Stress and wellbeing at work. In S. Zedeck (Ed.), APA handbook of industrial and organizational psychology, vol. 3: 359-398. Washington, DC: American Psychological Association.

Griffin, R. W., \& O’Leary-Kelly, A. M. (Eds.). 2004. The dark side of organizational behavior. San Francisco: Jossey-Bass.

Grzywacz, J. G., Carlson, D. S., Kacmar, K. M., \& Wayne, J. H. 2007. A multi-level perspective on the synergies between work and family. Journal of Occupational and Organizational Psychology, 80: 559-574.

Hackman, J. R., \& Oldham, G. R. 1976. Motivation through the design of work: Test of a theory. Organizational Behavior and Human Performance, 16: 250-279.

Hobfoll, S. E. 1989. Conservation of resources: A new attempt at conceptualizing stress. American Psychologist, 44: 513-528.

Hom, P. W., Mitchell, T. R., Lee, T. W., \& Griffeth, R. W. 2012. Reviewing employee turnover: Focusing on proximal withdrawal states and expanded criterion. Psychological Bulletin, 138: 831-858. 
Ibarra, H., \& Barbulescu, R. 2010. Identity as narrative: Prevalence, effectiveness, and consequences of narrative identity work in macro work role transitions. Academy of Management Journal, 35: 135-154.

Jackson, B., \& Parry, K. 2011. A very short, fairly interesting and reasonably cheap book about studying leadership (2nd ed.). Thousand Oaks, CA: Sage.

Keyes, C. L. M., Shmotkin, D., \& Ryff, C. 2002. Optimizing wellbeing: The empirical encounter of two traditions. Journal of Personality and Social Psychology, 82: 1007-1022.

Kilgannon, C., \& Robbins, L. 2010. Flight attendant had long imagined escaping down chute. New York Times. http://cityroom.blogs.nytimes.com/2010/08/11/. Accessed October 17, 2010.

Kleber, R. J., \& van der Velden, P. G. 2009. Acute stress at work. In C. L. Cooper, J. C. Quick, \& M. J. Schabracq (Eds.), International handbook of work and health psychology (3rd ed.): 269-291. Chichester, England: WileyBlackwell.

Korkki, P. 2013. Grand exits that never earn applause. New York Times, March 24: Bu8.

Kraimer, M. L., Shaffer, M., Harrison, D. A., \& Ren, H. 2012. No place like home? An identity strain perspective on repatriate turnover. Academy of Management Journal, 55: 399-420.

Kreiner, G. E., Hollensbe, E. C., \& Sheep, M. L. 2006. Where is the "me" among the "we"? Identity work and the search for optimal balance. Academy of Management Journal, 49: 1031-1057.

Ladge, J. J., Clair, J. A., \& Greenberg, D. 2012. Cross-domain identity transition during liminal periods: Constructing multiple selves as professional and mother during pregnancy. Academy of Management Journal, 55: 1449-1471.

Lazarus, R. S. 2000. Toward better research on stress and coping. American Psychologist, 55: 665-673.

Lee, T. H., Gerhart, B., Weller, I., \& Trevor, C. O. 2008. Understanding voluntary turnover: Path-specific job satisfaction effects and the importance of unsolicited job offers. Academy of Management Journal, 51: 651-671.

Lee, T. W., Mitchell, T. R., Holtom, B. C., McDaniel, L. S., \& Hill, J. W. 1999. The unfolding model of voluntary turnover: A replication and extension. Academy of Management Journal, 42: 450-462.

Lyness, K. S., \& Judiesch, M. K. 2001. Are female managers quitters? The relationships of gender, promotions, and family leaves of absence on turnover. Journal of Applied Psychology, 86: 1167-1178.

Maertz, C. P., Jr. 2012. Further clarifying proximal withdrawal states and the turnover criterion space: Comment on Hom, Mitchell, Lee, and Griffeth (2012). Psychological Bulletin, 138: 859-864.

Maertz, C. P., Jr., \& Campion, M. A. 2004. Profiles in quitting: Integrating process and content turnover models. Academy of Management Journal, 47: 566-582.

March, J. G., \& Simon, H. A. 1958. Organizations. New York: John Wiley.

Mobley, W. H., Griffeth, R. W., Hand, H. H., \& Meglino, B. M. 1979. Review and conceptual analysis of the employee turnover process. Psychological Bulletin, 86: 493-522.

Olson-Buchanan, J. B., \& Boswell, W. R. 2008. An integrative model of experiencing and responding to mistreatment at work. Academy of Management Review, 33: 76-96.

Park, T., \& Shaw, J. D. 2013. Turnover rates and organizational performance: A meta-analysis. Journal of Applied Psychology, 98: 268-309.

Petriglieri, J. L. 2011. Under threat: Reponses to and the consequences of threats to individual's identity. Academy of Management Review, 36: 641-662.

Picoult, J. 2010. Here comes a turnover storm. New York Times, October 17: Bu9.

Posthuma, R. A., Campion, M. C., Masimova, M., \& Campion, M. A. 2013. A high performance work practices taxonomy: Integrating the literature and directing future research. Journal of Management, 39: 1184-1220.

Pratt, M. G., Rockmann, K. W., \& Kaufmann, J. B. 2006. Constructing professional identity: The role of work and identity learning cycles in the customization of identity among medical residents. Academy of Management Journal, 49: 235-262.

Rothausen, T. J., Larson, A. M., \& Christenson, S. M. 2012. Expanding “desirability” of turnover: Hedonic and eudaimonic job satisfactions and wellbeing. Paper presented at the annual meeting of the Academy of Management, Boston.

Roy, K. M. 2006. Father stories: A life course examination of paternal identity among low-income African American men. Journal of Family Issues, 27: 31-54.

Ruiz, G. 2007. Role of workplace stress in turnover undervalued. Workforce. http://www.workforce.com/articles/ role-of-workplace-stress-in-turnover-undervalued. Accessed January 7, 2015.

Russell, C. J. 2013. Is it time to voluntarily turn over theories of voluntary turnover? Industrial and Organizational Psychology, 6: 156-173. 
Salamin, A., \& Hom, P. W. 2005. In search of the elusive U-shaped performance-turnover relationship: Are high performing Swiss bankers more liable to quit? Journal of Applied Psychology, 90: 1204-1216.

Shaw, J. D., Dineen, B. R., Fang, R., \& Vellella, R. F. 2009. Employee-organization exchange relationships, HRM practices, and quit rates of good and poor performers. Academy of Management Journal, 52: 1016-1033.

Silverman, D., \& Marvasti, A. 2008. Doing qualitative research: A comprehensive guide. Thousand Oaks, CA: Sage.

Snow, D. A., \& Anderson, L. 1987. Identity work among the homeless: The verbal construction and avowal of personal identities. American Journal of Sociology, 92: 1366-1371.

Sonenshein, S. 2006. Crafting social issues at work. Academy of Management Journal, 49: 1158-1172.

Sonenshein, S., DeCelles, K. A., \& Dutton, J. E. 2014. It's not easy being green: The role of self-evaluations in explaining support of environmental issues. Academy of Management Journal, 57: 7-37.

Super, D. E. 1990. A life-span, life-space approach to career development. In D. Brown \& L. Brooks (Eds.), Career choice and development (2nd ed.): 197-261. San Francisco: Jossey-Bass.

Vignoles, V. L., Ragalia, C., Manzi, C., Golledge, J., \& Scabini, E. 2006. Beyond self-esteem: Influence of multiple motives on identity construction. Journal of Applied Psychology, 90: 308-333.

Warr, P. 2007. Work, happiness, and unhappiness. Mahwah, NJ: Erlbaum.

Weick, K. E. 1995. Sensemaking in organizations. Thousand Oaks, CA: Sage.

Weick, K. E., Sutcliffe, K. M., \& Obstfeld, D. 2005. Organizing and the process of sensemaking. Organization Science, 16: 409-421.

Weiss, H. M., \& Rupp, D. E. 2011. Experiencing work: An essay on a person-centric work psychology. Industrial and Organizational Psychology, 4: 83-97.

Wright, T. A., \& Bonett, D. G. 1993. Role of employee coping and performance in voluntary employee withdrawal: A research refinement and elaboration. Journal of Management, 19: 147-161.

Wright, T. A., \& Bonett, D. G. 2007. Job satisfaction and psychological wellbeing as nonadditive predictors of workplace turnover. Journal of Management, 33: 141-160.

Wrzesniewski, A., McCauley, C., Rozin, P., \& Schwartz, B. 1997. Jobs, careers, and callings: People's relations to their work. Journal of Research in Personality, 31: 21-33. 